\title{
10 passeios pelos bosques da ficção - Entrevista concedida por Milton Hatoum a Denis Leandro Francisco
}

1

Um certo silêncio atravessa toda a narrativa de Relato de um certo Oriente. Muitas personagens - a narradora anônima, Hakim, opai, Emir, o fotógrafo Dorner e a criança Soraya Ângela, para citar alguns - carregam consigo uma espécie de indice desse silêncio. Por que esse silêncio?

MH: O silêncio de Soraya Ângela é um impedimento físico. Ela é surdamuda, e se expressa por meio de gestos, sobretudo pelo olhar. O mundo dela é sensorial: auditivo, visual, olfativo, de modo que suas emoções e sentimentos passam pelo corpo, pelos gestos. Sempre quis inventar uma personagem que falasse através do corpo, não da voz. E fui encontrá-la na minha infância, pois convivi com uma prima assim. O silêncio dos outros personagens tem mais a ver com as reticências da memória e com os traços específicos de cada personagem.

2. Poderíamos, ainda, associar esse silêncio a um certo fracasso da linguagem? a essa inadequação fundamental da linguagem ao real? como se, não podendo a linguagem capturar/recuperar completamente um acontecimento ou alguém, as personagens optassem, então, pelo silêncio?

MH: A linguagem literária não explicita nem explica a realidade. Penso que a literatura não deve ser explicativa. Quem deve explicar a literatura é o ensaio, a crítica. Escrever ficção já é um ato de desvio, de distração da realidade. A literatura é um dos modos de se ver o mundo, e, a meu ver, um modo oblíquo, que se esconde para revelar uma outra realidade: a do texto construído pela linguagem. E o silêncio, a lacuna, o inaudito são maneiras de expressar essa inadequação com o real. O personagem 
que você mencionou (Soraya Ângela) vive, ou sobrevive, por meio desse silêncio, que é sua maneira de estar no mundo e lidar com ele.

3. A memória é a matéria de todo o romance, tradicional ou moderno. Em Relato de um certo Oriente, a memória não é apenas tematizada, funcionando como espírito tutelar, mas faz parte também da própria estrutura do romance que, com seus inúmeros avanços e recuos da narrativa, constitui-se como um "labirinto temporal". Seria possivel uma leitura do texto como a passagem de uma tentativa exaustiva de captura integral da memória, captura integral do passado e da história via memória (como parece ser a intenção inicial da narradora), para, finalmente, chegar-se à constatação e demonstração de que toda memória é falha, lacunar e carrega consigo uma componente que é a invenção, já que "o 'eu' que narra no presente é um indice que permanece constante, mas essa constância é ambigua, pois o narrador era 'diferente' do que é boje"'?

MH: No Relato tentei fazer da memória um tema que se desdobra em várias direções da narrativa. Memória dos personagens, que, por sua vez, evocam espaços afetivos da casa, da cidade, do passado de cada um confrontado ou em diálogo com o passado do outro. Foi um esforço no sentido de armar um mosaico estilhaçado nesse labirinto temporal a que você se referiu. Por outro lado, a construção desse espelho do passado é sempre inacabada, lacunar. Lembrar de algo já é um convite ao esquecimento, e é nessa falha da memória que a invenção ou a imaginação age com liberdade, sem amarras. Daí o fato de que toda autobiografia pode ser uma invenção, mesmo involuntária. Se eu quiser contar tudo, rigorosamente tudo o que aconteceu ontem na minha vida, certamente vou esquecer muitos detalhes, inúmeros gestos, palavras, um insulto, uma risada, um bocejo, um momento de sonolência ou de ânimo, etc. Só um louco pode se lembrar de tudo. Aliás, esta é a história de Funes, el memorioso, de Jorge Luis Borges. Funes é um personagem que se recorda de tudo, ou seja, vive numa insônia sem fim.

${ }^{1}$ HATOUM, 1996, p. 13. 
4. Em seu texto Literatura e memória: notas sobre Relato de um certo Oriente, o Sr. diz ter posto de lado o projeto de um romance espacial, de grandes panorâmicas sobre a região amazônica, e que resolveu fechar a angular, usando uma lente de aumento, para ver de perto um drama familiar. Como se articulam, em seu texto, esse drama familiar, esse silêncio e a memória?

MH: Bom, aí eu convido o leitor crítico para dar essa resposta. O romance, enquanto gênero, sempre abordou dramas familiares, porque narra uma história de um ou vários indivíduos. Nem sempre diz respeito a uma família, mas é como se fosse um clã mais ou menos fechado. O silêncio e a memória se articulam com a estratégia narrativa, ou seja, com a própria arquitetura do texto. O Relato foi mais "planejado" que o Dois irmãos. Proust dizia que a maturidade anula a espontaneidade de certas atitudes, e isso também em relação à escrita. Confesso que quando escrevi o Relato, não sabia aonde ou como aquele arabesco ia acabar. Foi um livro escrito durante a noite e a madrugada. Depois, reescrevi muitas vezes... Com o Dois irmãos, foi uma atitude completamente diferente.

5. "Dados acumulados, e com freqüência inconscientes que afluem à memória". ${ }^{2}$ Esse conceito benjaminiano de experiência parece participar, em profundidade, da construção do seu romance. Em que medida esse conceito subjaz à narrativa?

MH: Na medida que a experiência é fruto de uma tradição cultural, lingüística, histórica. A noção de experiência não se restringe a algo empírico ou vivido. Há um lado subjetivo e reflexivo na experiência, alguma coisa que vem da tradição oral e do acúmulo de certos fatos que, muito tempo depois, tornam-se imagens e sons na nossa memória. E isso até mesmo no vocabulário que a gente usa. Por exemplo, quando eu quis indicar um "menino" no Dois irmãos, fui levado a usar a palavra "curumim". Se eu tivesse usado "piá", "guri" ou "moleque", estaria falseando uma cultura e subtraindo da minha memória uma palavra muito usada na minha infância manauara.

${ }^{2}$ HATOUM, 1996, p. 12. 
6. "Pensar nas origens é pensar na sua perda, e assim tentar reatar um nexo com as origens, uma ponte que não é incompativel com a História". ${ }^{3}$ Essa perda irrecuperável das origens, essa busca impossivel parece fortemente simbolizada pela narradora que regressa à casa de sua infância. Ela mesma afirma, a respeito da mãe biológica: "Minha bistória com ela é a história de um desencontro". "Que ponte "compativel" é essa entre as origens e a História se essa busca é a busca impossivel de uma presença também impossivel e se essa história é a bistória de um desencontro?

MH: A busca das origens me parece algo impossível... Ou então apenas isso: uma busca, uma tentativa. Não acredito que haja, no indivíduo, nas sociedades e nos países, origens bem delimitadas. Por exemplo: sou um brasileiro, minha mãe é amazonense e meu pai era libanês... Se eu for atrás de todas as origens (maternas e paternas), vou acabar enlouquecendo. Posso descobrir que meu parente paterno mais distante no tempo era um fenício, mas os fenícios circularam por todo o Mediterrâneo e também pela África. Posso acabar em Cartago ou em Roma ou na Sićlia. Nossas origens são sempre misturadas e difusas. E as culturas, bem como as sociedades, são vasos comunicantes. Por isso acho perigosas certas "teorias" forjadas pela elite norte-americana, como a do "choque de civilizações", de Samuel Huntington. É como se tivesse existido desde sempre no Ocidente uma essência imutável, petrificada, imune ao processo histórico, inclusive às devastações causadas pelo colonialismo e o imperialismo. No fundo, são teorias racistas, que falam de um "Nós" com um olhar superior e dominador. Do ponto de vista da ficção, penso que o encontro e o desencontro são motivos literários, romanescos por excelência. O romance evoca um desejo que nunca se realiza em sua plenitude... ou persegue um objeto que é esquivo, fugidio.

7. Relato de um certo Oriente exibe uma árdua luta com o ponto de impossível da linguagem e, por extensão, com o ponto de impossível da memória, ou trata-se, não de uma luta, mas, antes, de uma demonstração

\footnotetext{
${ }^{3}$ HATOUM, 1996, p. 9.

${ }^{4}$ HATOUM, 1989, p. 162.
} 
dessa impossibilidade, demonstração de que "o invisível não pode ser transcrito e sim inventado"?

$\mathrm{MH}$ : Isso me faz lembrar um conto de Jorge Luis Borges, em que o personagem tenta fazer um mapa de uma cidade na escala natural. Ou seja, o mapa é ou seria a própria cidade, o que é um absurdo, uma aberração, e, é claro, uma tremenda ironia borgiana. Escrever ficção é uma tentativa de inventar outra realidade, e não de espelhar ou reproduzir a realidade em que vivemos. A frase que você citou é mais ou menos isso: não se escreve sobre a realidade, mas a partir de alguma coisa que existiu ou pensamos ter existido. O tempo que passou, o tempo vivido, é o grande pretexto do escritor.

8. Pensando a relação entre o texto literário e a História, o que há de positivo e o que há de negativo se tomarmos como fato que o passado - individual e coletivo - não nos abandona, que ele de fato é, como afirma a narradora anônima de seu primeiro romance, "um perseguidor invisivel, uma mão transparente" acenando a cada novo instante que se apresenta ao indivíduo e ao grupo social?

MH: O passado morto, cristalizado, não interessa à literatura. Manuel Bandeira dizia que o passado só existe realmente quando pulsa no presente. A força mais consistente do passado só se revela na medida em que é dramatizado no tempo em que vivemos, e também no interior da escrita. Em maior ou menor grau, o indivíduo e a História podem aparecer numa ficção. Na obra de Clarice Lispector, o drama do personagem, sua subjetividade, suas indagações ontológicas, tudo isso é mais importante para o narrador do que a perspectiva histórica. O inverso disso se encontra na obra de Érico Veríssimo, por exemplo. Um escritor como Joseph Conrad soube conciliar o olhar interior com a ação. É como se o mar fosse uma metáfora do movimento, do deslocamento no espaço e também de uma reflexão sobre o drama moral do ser humano. Um movimento que vai da superfície à profundeza, pois as viagens dos narradores de Conrad esbarram num impasse moral, que é o verdadeiro destino da narrativa.

\footnotetext{
${ }^{5}$ HATOUM, 1989, p. 126.

${ }^{6}$ HATOUM, 1989, p. 166.
} 
9. Ainda a propósito de Relato de um certo Oriente, o Sr. diz que "dar forma, forjar por meio da linguagem um pequeno pedaço do passado" foi uma das intenções do seu romance. Essa intenção: desejo de retorno a um certo "paraíso que jamais existiu" - o passado, a infância, a casa materna - ou, ao contrário, utilização salutar das potencialidades da linguagem e da memória como resposta possivel às adversidades do real, espécie de espelho para vencer essa medusa com a qual esbarramos todos os dias?

MH: Sim, e um escritor só escreve sobre algo que não pode deixar de escrever. Alguma coisa que o incomoda ou provoca ou lhe traz inquietação. Tenho a impressão de que alguém escreve porque se sente de alguma maneira "fora do lugar", o título do belo livro de Edward Said. Depois de ter publicado meu segundo romance (Dois irmãos), perguntei a mim mesmo: por que elegi como narrador dos dois livros um personagem descentrado, sem lugar definido na família, ou cujo lugar fosse um não-lugar? Então pensei, sem concluir nada de definitivo, que a minha vida foi marcada por rupturas sucessivas, por passos mais ou menos perdidos no Brasil e no exterior, sobretudo por um sentimento de não pertencer totalmente a uma única região brasileira. O fato de não me adaptar à cidade em que nasci, de ser filho de imigrantes, de ter saído sozinho do "meu" lugar, tudo isso pode ter influído na escolha desses narradores e personagens erradios.

10. Recentemente, em uma conferência sobre tradução, na UFMG, o Sr. disse, respondendo à pergunta de um participante, que o papel do escritor no mundo de boje é equivalente ao de qualquer outro profissional, de qualquer outro trabalho - o de exercer uma função social-, rejeitando, assim, qualquer "auratização" da função do escritor. Gostaria de mudar o foco da pergunta: para o escritor, professor e crítico literário Milton Hatoum, qual é o papel, não do escritor, mas da escrita e, principalmente, da leitura para o sujeito?

\footnotetext{
${ }^{7}$ HATOUM, 1996, p. 12.

${ }^{8}$ Termo empregado por GANTHERET, 1984, p. 77.
} 
MH: O texto ficcional, uma vez publicado, adquire autonomia, desgarrase do autor empírico e pode ser lido de várias maneiras, que dependem do enfoque de cada leitor. Falar sobre o papel da leitura para o sujeito pressupõe o conhecimento de ambos. Qual leitura? Qual sujeito? Daí a importância da universidade, da escola, do ensino de literatura de um modo geral. Todo o meu esforço durante mais de quinze anos em sala de aula foi no sentido de apresentar aos estudantes e ler com eles algumas obras significativas da literatura. No começo eu fazia uma leitura "impressionista" da obra; depois recorria aos ensaios críticos sobre esse texto, e nesse momento eu percebia que a crítica tinha um papel decisivo na leitura. Dentre outras coisas, criticar é descobrir relações simbólicas e sociais, que muitas vezes estão ocultas. Isso sem contar certos enigmas, insolúveis talvez para sempre. Então cada leitor, dependendo de sua experiência de vida e intelectual, constrói ou inventa a sua leitura. Penso que nesse momento a fronteira entre leitura e ficção é ambígua. Foi o que Jorge Luis Borges tentou fazer ao escrever a resenha de um livro apócrifo. A escrita inventa um mundo para o sujeito, e este, sendo um leitor crítico, nos ensina a ver esse mundo narrado sob outros ângulos, mais variados e complexos, muito além da superfície, da uniformidade e das convenções da realidade.

\section{Referências Bibliográficas}

GANTHERET, François. Incertitude d'éros. Paris: Gallimard, 1984.

HATOUM, Milton. Literatura e memória: notas sobre Relato de um certo Oriente. São Paulo: PUC, 1996.

HATOUM, Milton. Relato de um certo Oriente. São Paulo: Companhia das Letras, 1989. 